\title{
Influencing Factors for the Instability and Collapse Mode of the Goaf Structure in a Gypsum Mine
}

\author{
Zhaowen Du $\mathbb{D}^{1}{ }^{1}$ Zhihe Liu $\mathbb{D}^{1,2}$ Rui Liu, ${ }^{1}$ Sheng Wang, ${ }^{1}$ and Faxin Li $^{1}$ \\ ${ }^{1}$ College of Energy and Mining Engineering, Shandong University of Science and Technology, Qingdao 266590, China \\ ${ }^{2}$ School of Resources and Environmental Engineering, Shandong University of Technology, Zibo 255000, China \\ Correspondence should be addressed to Zhihe Liu; liuzhihe@sdut.edu.cn
}

Received 28 January 2021; Revised 7 March 2021; Accepted 18 March 2021; Published 27 March 2021

Academic Editor: Jia Lin

Copyright (c) 2021 Zhaowen Du et al. This is an open access article distributed under the Creative Commons Attribution License, which permits unrestricted use, distribution, and reproduction in any medium, provided the original work is properly cited.

Large-area goafs in a gypsum mine tend to collapse after 10 or more years, but the influencing factors are still unclear, and the effects of multiple factors have not been comprehensively considered. In this study, the failure mechanism and collapse mode of the room-pillar goaf structure were analyzed, and the uniaxial compressive strength tests of the pillars under different conditions were carried out in a laboratory. The influences of water, temperature, and time on the strength of the gypsum rock were considered. These three factors weakened the gypsum rock in different degrees. After 120 days of immersion, water had the greatest effect with a strength-weakening rate of $52.61 \%$. After 20 temperature cycles, changes in temperature had little effect with a strength-weakening rate of $12.60 \%$. After 25 years of aging, the strength-weakening rate of time was $25.13 \%$. These results show how different factors affect the instability and collapse of the goaf structure, which are of great significance for predicting and preventing this from happening.

\section{Introduction}

Gypsum is an important mineral resource and widely used in various fields [1-3]. At present, gypsum is mined with the room pillar method, with multiple pillars supporting the working space and isolated pillars supporting the isolated mining unit [4-6]. The room pillar method leads to large-area goafs, which can become a major hazard $[7,8]$. The instability and collapse of goafs are sudden and instantaneous [9-11]. With an obvious long-term lag effect, this makes it difficult to predict, prevent, and control the collapse behavior, which becomes a major safety issue for gypsum mines. Many researchers have studied the stability of gypsum pillars and rooms. Lu et al. [12] improved the damage evolution constitutive equation of a gypsum rock mass considering the characteristics of the surrounding rock. They found that an ore pillar should have a factor of safety greater than 1.5 , and the pillar width greater than $4.3 \mathrm{~m}$. Zhou et al. [13] proposed a simplified mechanical model of a gypsum column based on the given stress-strain relationship of gypsum rock, which they used to study the instability mechanism of a gypsum room-pillar system. They found that the peak pressure after strain softening and the surrounding humidity can increase the stiffness of the support system. Xia et al. [14] established a new viscoelastic model to solve the creep failure of the mine roof by considering the rheology of a gypsum rock mass. They found that the deflection of the roof increases with time. Wang et al. [15] developed a physical model for the failure mode of a multipillar support system and found that the failure of any supporting member would cause settlement. Chen et al. [16] built a cusp catastrophe model for the support system where beams and pillars release and dissipate energy, respectively, in the plastic zone. They found that the instability of the support system is caused by uncoordinated energy release, energy dissipation, and geometric deformation. Xu et al. [17] used case studies to evaluate the pillar stability under site-specific rock mass conditions and established a correlation between the strain and aspect ratio. Jessu and Spearing [18] studied the influence of a typical fault on the stress and displacement of a goaf in a gypsum mine; they found that the loads on the roof and pillar are negatively correlated with distance from the fault. Zhang et al. [19] proposed a method to evaluate the condition of masonry pillars. Their results showed that ultrasonic stress waves can be used to monitor 
the internal structure of a pillar. Zielińska and Rucka [20] conducted an experimental study on the creep of red sandstone under step loading. Xie and Gong [21] analyzed the influence of the temperature and surrounding rocks on the strength and deformation of weathered granite under freezethaw conditions. Shen et al. [22, 23] studied the influence of geological characteristics on overburden failure in the process of working face mining by means of restricted equilibrium and continuous numerical methods; then, they concluded that the influence characteristics of goaf stability mainly varied with different lithologies. Zhou et al. [16, 24] conducted a comprehensive evaluation of the goaf risk by combining mattering element analysis with numerical simulation; then, they obtained a relatively objective and reasonable comprehensive evaluation method.

The previous studies mainly focused on establishing a mechanical or failure evaluation model to judge or predict pillar failure according a certain influencing factor. However, the instability of a gypsum pillar is affected by many factors. In this study, the large-area goaf structure formed after many years in the Luneng Gypsum Mine was used to analyze the stress characteristics and failure modes generated by the room pillar method. The effects of water and temperature on the strength of the gypsum rock were considered. Then, the variation in strength of gypsum rock pillars at different positions and ages was tested. This paper aims to grasp the influence of different factors on the instability of the goaf structure to provide a theoretical basis for maintaining the stability of goaf, so as to promote the sustainable development of mining.

\section{Theory}

2.1. Mechanism of a Mining Unit. The main types of instability and collapse of the gypsum mine are as follows: (I) single-pillar instability and overlying strata stability in goaf, (II) single-pillar instability and overlying strata overall instability and collapse in goaf, (III) multiunit instability and collapse impact in goaf, (IV) group structure "domino-type" instability and collapse impact in goaf, and (V) impact form of large-area group collapse in goaf. The room pillar method is commonly used for gypsum mines; it relies on a large number of pillars to support the working space, and isolated pillars support isolated mining units. Figure 1 shows the structural model. The stability of a mining unit mainly depends on the geometric parameters of the pillars and room: the room span $l$ and pillar side length $d$, as shown in Figure 2. The mechanical model of an overburdened rock beam can be used to solve for the limit span of the roof plate and analyze the stability of the mine room [25-27]. The tributary area method can be used to solve for the stress state of a pillar and analyze its stability, which in turn can be used to determine the stability of the mining unit.

2.1.1. Stability of a Mine Room. According to the classical rock beam theory of mine pressure, the initial state of the protective gypsum plate is a fixed beam at both ends. The maximum bending moment of the protective gypsum plate is at the end of the mine room, which is given by MFixed_end $=q \mathrm{l} 2 / 12$. When the cracks appear at the end of the protective gypsum plate, the entire structure becomes a simply supported beam, as shown in Figure 2. There are two failure modes for the protective gypsum plate: bending tensile failure and shear failure [16]. The maximum bending moment of the protective gypsum plate is at the middle and is given by Mmid $=q 12 / 12$. Then, the maximum tensile stress at the middle of the protective gypsum plate is

$$
\sigma_{\mathrm{Mid}}=\frac{M_{\mathrm{Mid}}}{W}=\frac{q l^{2}}{2 m_{0}},
$$

where $W$ is the interface modulus of the rock beam $W=$ $m_{0} / 6$ and $m_{0}$ is the thickness of the protective gypsum plate $(m)$. When the maximum tensile stress at the middle of the protective gypsum plate is greater than the ultimate tensile strength of the gypsum rock (i.e., $\sigma_{\mathrm{Mid}} \geq\left[\sigma_{t}\right]$ ), the protective gypsum plate is damaged by bending tension. Thus, the limit span of bending tensile failure of the protective gypsum plate can be solved as follows:

$$
l_{\text {Pull }} \geq \sqrt{\frac{2 m_{0} \sigma_{t}}{q}} .
$$

When the protective gypsum plate cracks, the maximum shear force at the end is $Q_{\text {End }}=(q l / 2)$.

When the maximum shear stress at the end exceeds the ultimate shear strength of the gypsum rock (i.e., $\tau_{E n d} \geq[\tau]$ ), the whole end of the room caves owing to shear failure of the protective gypsum plate. Thus, the limit span of the protective gypsum plate for shear failure can be solved as follows:

$$
l_{\text {Shear }} \leq \frac{4 m_{\text {Residual }}[\tau]}{3 q} .
$$

To ensure that the protective gypsum plate will not be damaged, the limit span of the room should be

$$
l_{0}=\min \left[l_{\text {Pull }}, l_{\text {Shear }}\right] .
$$

Generally speaking, due to the existence of bending tension as well as the presence of fractures, the protective gypsum plate tends to fail.

2.1.2. Pillar Stability. The pillar is loaded by the overlying strata, and its stability directly determines the stability of the overlying rock in the mining unit. There are many methods to calculate pillar load, such as empirical formulas, the effective load method, and the tributary area method [28]. In this study, the tributary area method was used to calculate the effective load on a pillar, as shown in Figure 2. The pillar load is given by $Q=q(d+l)^{2}$. When the pillar stress exceeds the ultimate compressive strength (i.e., $\sigma_{\mathrm{Pre}} \geq \sigma_{c}$ ), the pillar is damaged and destabilized, which resulted in the overall instability and caving of the lower part of the key stratum in the mining unit. Thus, the limit size of the pillar to ensure stability can be obtained as follows: 


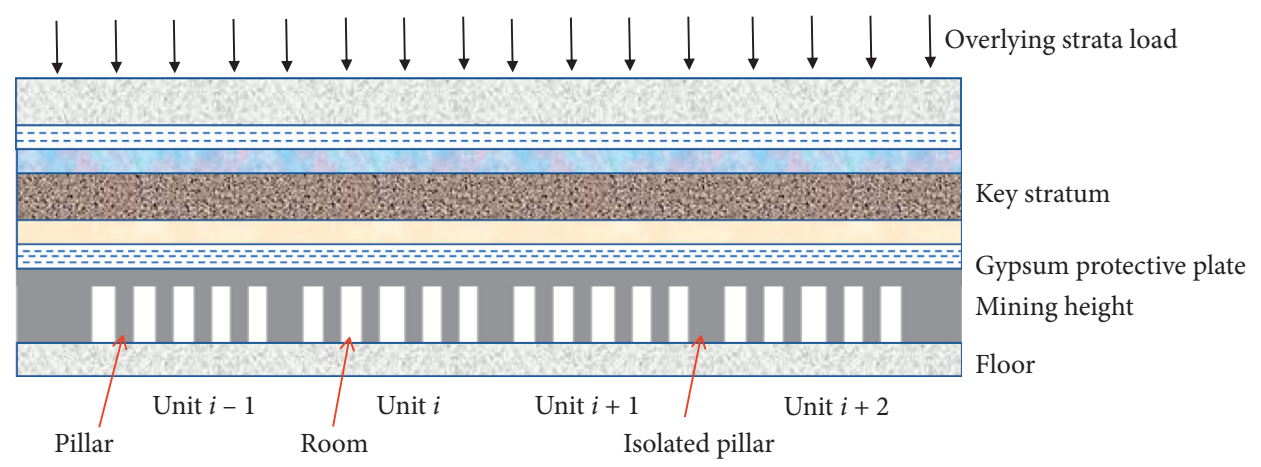

FIgURE 1: Spatial structure of overlying strata for a room-pillar gypsum mine.

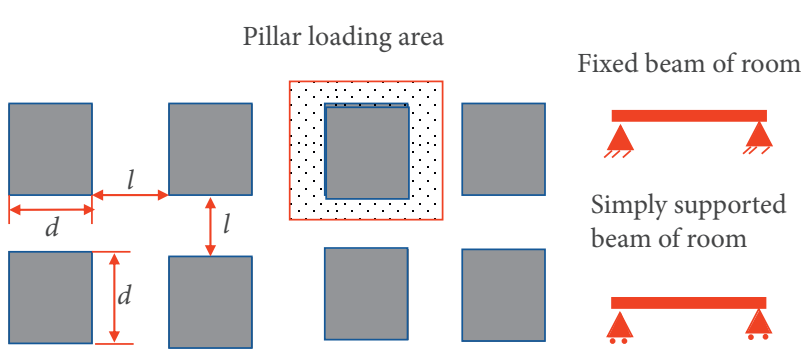

FIgURE 2: Mechanical model of a room pillar mine.

$$
d_{0}=\frac{l}{\sqrt{\left(\sigma_{c} / q\right)}-1}
$$

When the room is smaller than the limit span $\left(l \leq l_{0}\right)$ and the pillar is larger than its limit size $\left(d \geq d_{0}\right)$, the room and pillar can remain stable during the mining process. If they are not, the room and pillar will be destroyed and will destabilize the mining unit.

2.2. Modes of Instability and Collapse. At present, there are two structural collapse and instability modes in the gypsum mine goaf: room failure and pillar failure [29-33].

2.2.1. Instability Mode Induced by Room Failure. When a room is larger than the limit $\operatorname{span}$ (i.e., $l \geq l_{0}=\min$ $\left.\left[l_{\text {Pull }}, l_{\text {Shear }}\right]\right)$, it is gradually damaged by the mining process. Most rooms fail in tension. A failure arch structure forms and gradually develops upward to the bottom of the key stratum, which results in the destruction of the pillar, as shown in Figure 3. After the room and pillars in the mining unit are destroyed, the load of the critical stratum and overlying strata is transferred to an isolated pillar, resulting in stress concentration. In general, the collapse evolution process of this instability mode is relatively slow. Although the mining unit will collapse, if the key stratum remains stable, a serious accident will not occur. For actual sites, the geometric parameters are generally far less than the limit span of the mine room. However, a large amount of on-site accidents in available data shows that even if the mine room is far smaller than the limit span, the protective gypsum plate is gradually weathered and collapsed under the influence of various factors such as water, temperature, and mining disturbances, as shown in Figure 4.

2.2.2. Overall Unit Instability Mode Induced by Pillar Failure. When a pillar is less than the stability limit size (i.e., $\left.d \leq d_{0}=l /\left(\sqrt{\left(\sqrt{\sigma_{c}} / q\right)}-1\right)\right)$, it may suddenly fail and destabilize during the mining process. This results in the overall collapse of the protective gypsum plate and the soft rock strata above up to the upper key stratum, as shown in Figure 5. After the pillar and room are destroyed, the load of the key stratum and overlying strata is transferred to an isolated pillar, which results in a stress concentration. The instability and collapse mode develop rapidly, and it can be induced by an impact. The state of a gypsum mine goaf is complex, and a pillar is affected by water, mining disturbances, and other factors. The accident data of on-site disasters prove that even large pillars have a high risk of later failure and instability, which is why current pillars are far greater than the size that leads to ultimate failure, as shown in Figure 6.

Therefore, the collapse mode of goaf can be changed by adjusting the thickness of roof protection and the unit size of goaf, such as increasing the thickness of roof protection and decreasing the unit size.

\section{Experimental Study on the Influencing Factors for the Instability and Collapse of the Room Pillar Structure}

The room pillar method has formed stable and large-area goafs in the gypsum mine. Over time, a collapse may occur; this indicates a long time lag resulting from the combined effects of many external factors. This part takes the Luneng Gypsum Mine as a case to study the weakening effects of water, temperature, and age on gypsum rock.

3.1. Methodology. At the same pillar location of the gypsum mine, the original gypsum rock were obtained and transported to the laboratory. Through rock coring equipment, the original rock is processed into a standard rock mechanics test specimen: cylindrical $(\Phi 100 \times 50 \mathrm{~mm})$. Then, the second screening and wave velocity test are carried out on the specimens, and the specimens with no obvious joint cracks 


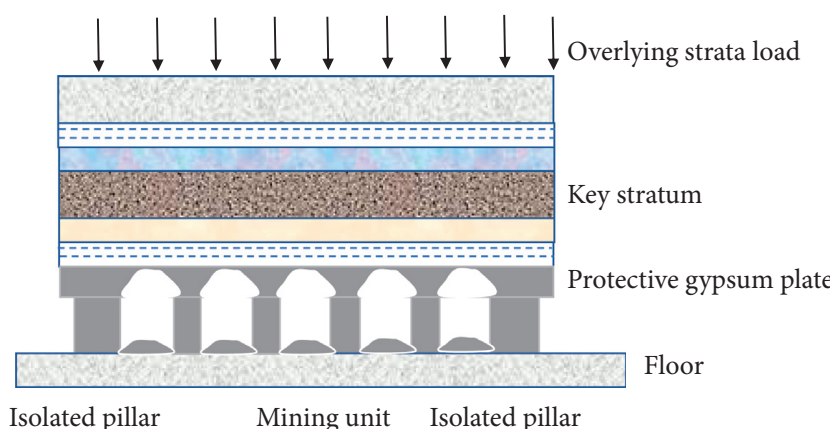

(a)

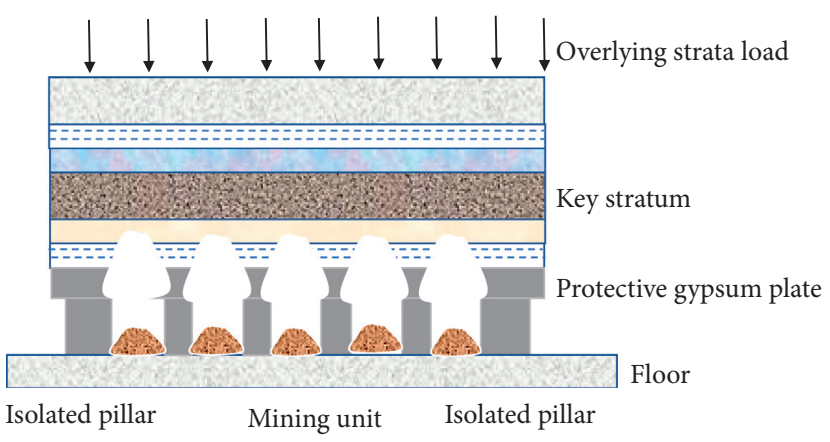

(b)

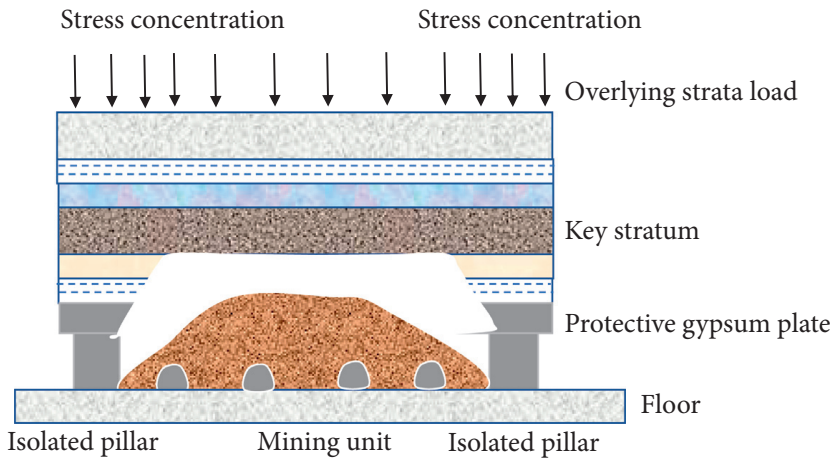

(c)

FIgURE 3: Progressive failure mode of a mining unit induced by room failure: (a) cracking and caving of the protective gypsum plate, (b) upward development of the arch structure, and (c) overall failure of the room pillar structure with stable suspension of the key stratum.
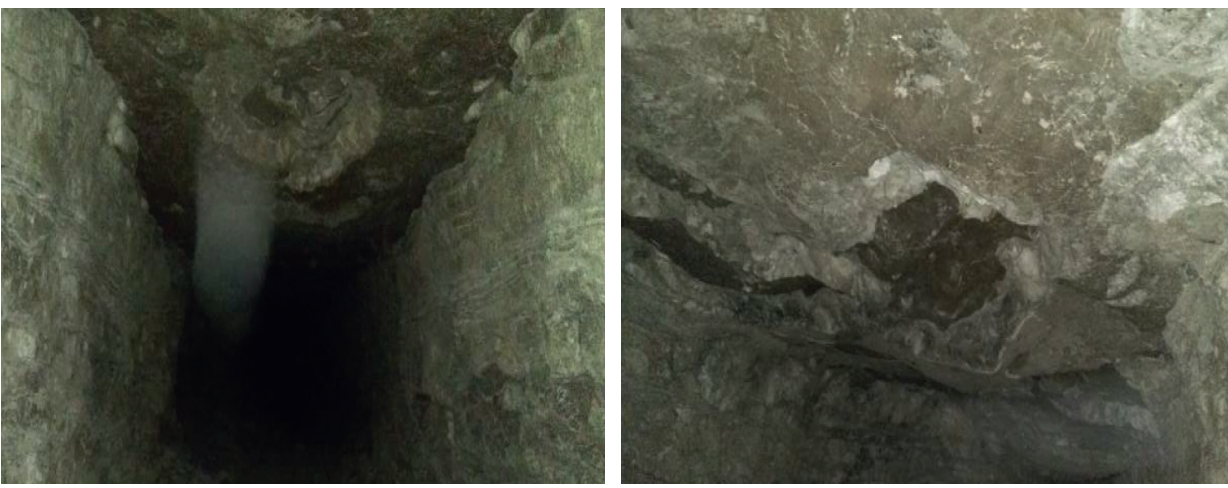

FIGURE 4: Weathering damage of a gypsum mine room.

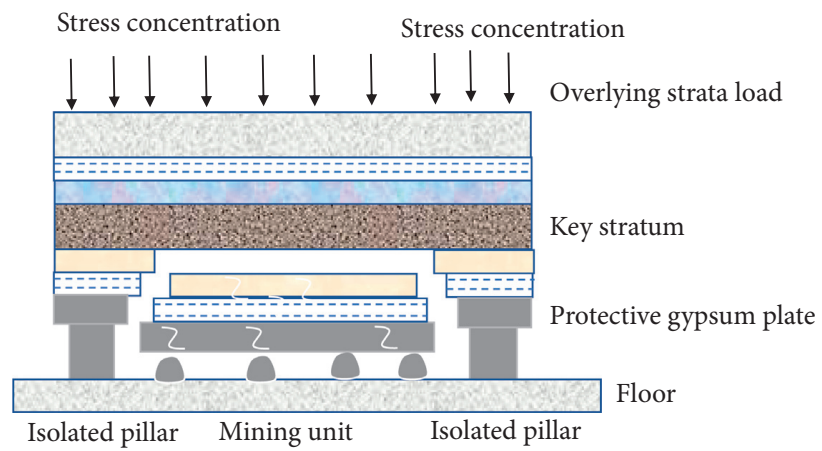

Figure 5: Overall instability mode induced by pillar failure. 

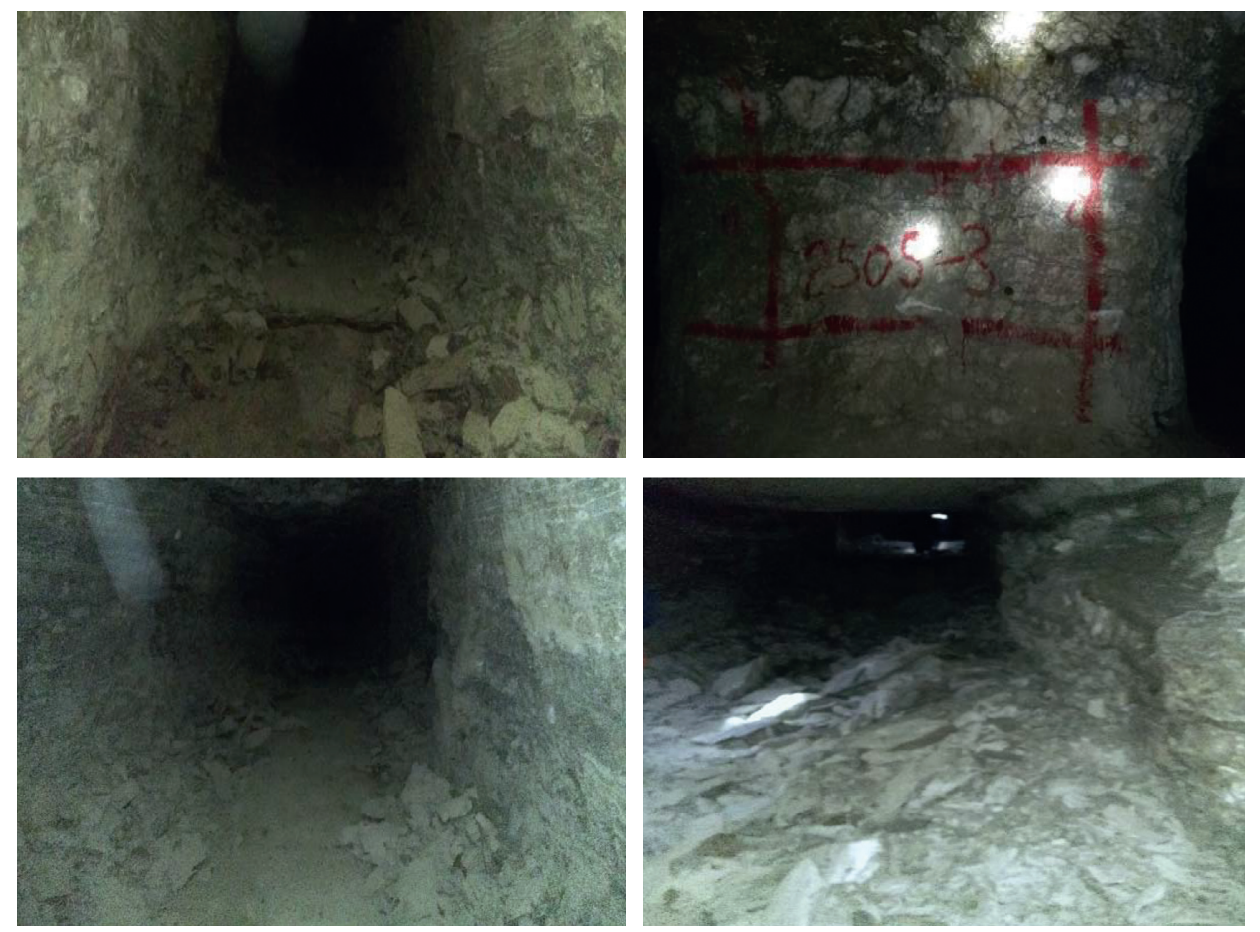

Figure 6: Weathering damage of gypsum mine pillars.

on the surface and little difference in wave velocity are selected as the final specimens of this test.

\subsubsection{Experimental Design and Process of Water Effects.} Gypsum mines are susceptible to water, and some accidents have shown that water contributes to goafs' instability and collapse The presence and amount of water affect the mechanical properties of gypsum rock [34-38]. In this study, the uniaxial compressive strength of gypsum rock was used as the evaluation parameter, and the strength-weakening rate was taken to quantify the effect of water on gypsum rock. The natural water content of gypsum rock is $2.17 \%$. Gypsum rock specimens were immersed in water for different amounts of time (1-120 days). The uniaxial compressive strength of the gypsum rock was then measured, and the strength-weakening rate was determined. Figure 7 shows the experimental process.

3.1.2. Experimental Design and Process of Temperature Effects. Through an analysis of collapse accidents of gypsum mine goafs, it is shown that the collapse accidents of the goafs mostly occur in spring and winter, especially for loose goafs. This indicates that changes in temperature due to seasons may have a weakening effect. Therefore, the strength-weakening effect of temperature cycles on gypsum rock was considered [39-41]. Specimens were placed in different temperature environments to simulate the four seasons. Figure 8 shows the specific experimental process, which is detailed as follows:

(1) Spring: specimens were placed in a refrigerator at a set temperature of $4^{\circ} \mathrm{C}$
(2) Summer: specimens were placed in an incubator at a set temperature of $30^{\circ} \mathrm{C}$

(3) Autumn: specimens were placed in a refrigerator at a set temperature of $4^{\circ} \mathrm{C}$

(4) Winter: specimens were placed in a refrigerator at a set temperature of $-10^{\circ} \mathrm{C}$

Each stage was $4 \mathrm{~h}$, and a cycle comprised all four stages. During the experiment, the gypsum specimens were sealed with the film to ensure that the moisture content remained stable and to eliminate the influence of water. After each cycle, the wave velocity of the specimen was tested. The uniaxial compressive strength was tested after the specimen was kept for $24 \mathrm{~h}$ at room temperature. Specimens were subjected to up to 20 cycles, which represented 20 years.

Each stage was $4 \mathrm{~h}$, and a cycle contains all four stages. During the experiment, the gypsum specimens were film-sealed to ensure that the moisture content remained stable and to eliminate the influence of water. After the end of each cycle, the wave velocity of the specimen was tested. The uniaxial compressive strength of the specimen was tested after being stored for $24 \mathrm{~h}$ at room temperature. Specimens were subjected to up to 20 cycles, which represented 20 years.

3.1.3. Experimental Design and Process of Time Effects. The goafs of a gypsum mine created by the room pillar method often remain intact for several years or even decades before collapse. Under long-term stress, the stability and lag collapse of a gypsum mine goaf depend to a large extent on the ultimate support capacity of the gypsum ore pillars over time [42-47]. The uniaxial compressive strength test was 

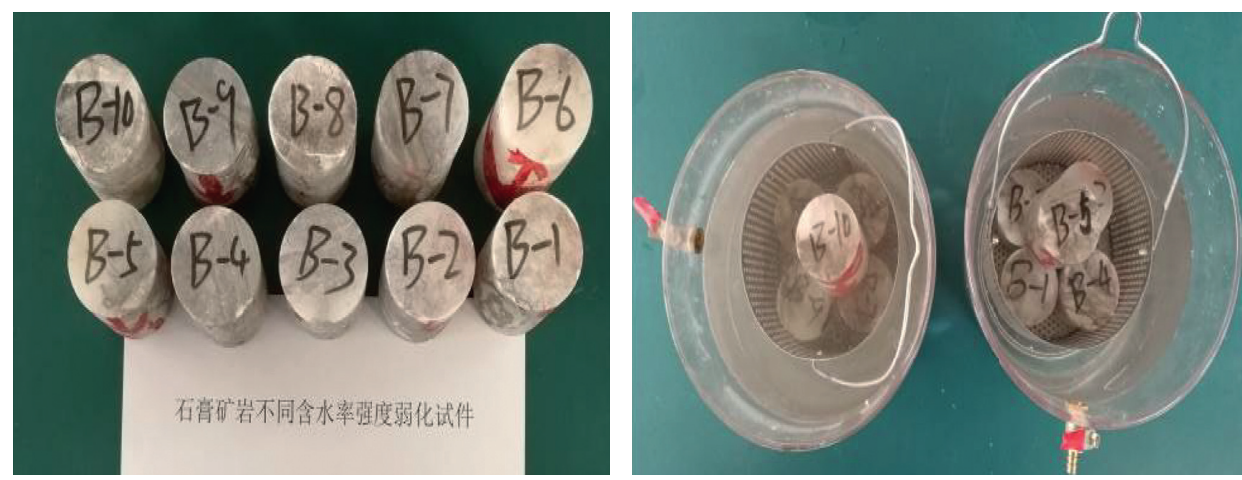

Figure 7: Water immersion test of gypsum rock specimens.
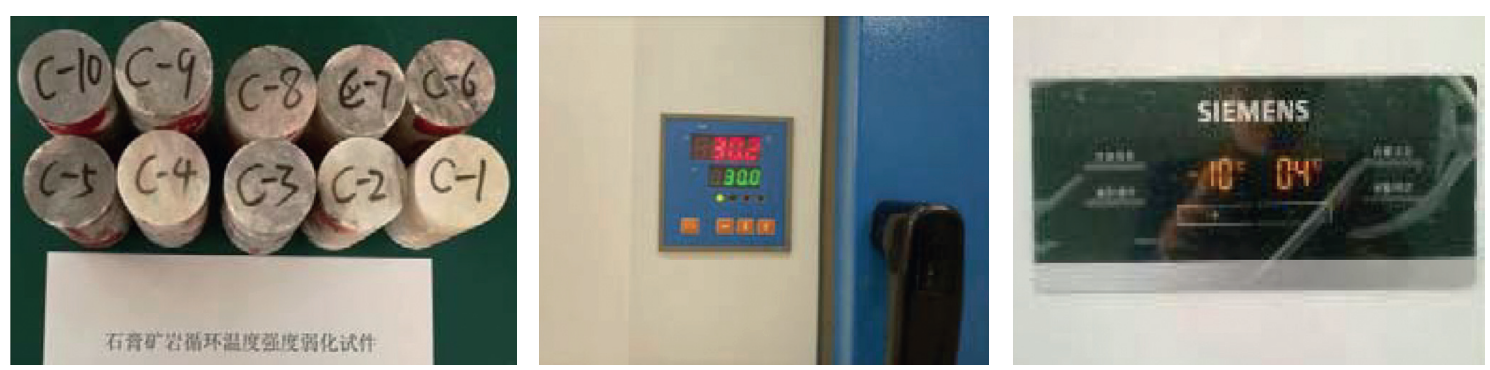

FIgURE 8: Experiments on the influence of the cycle temperature.

carried out on the large-area goaf specimens of the Luneng Gypsum Mine. The strength-weakening rate was taken as the key parameter to evaluate the effect of age.

When a room in a gypsum mine is exhausted, the resulting goaf should be sealed. A goaf has no water or power supply. Over time, the conditions in the goaf become complex and changeable, and the risk to workers entering the goaf is high. This led to many difficulties with taking specimens. With the help of on-site engineers and technicians, a simple and portable sampling equipment was designed that comprises an electric drill, battery, and coring sleeve.

To ensure personnel safety, gypsum rock pillars were mainly sampled from the relatively stable II-1 gypsum stratum. Three to five pillars with good integrity were selected to specimen different ages. The coring position was $1.0-1.5 \mathrm{~m}$ from the bottom of the gypsum pillar. The coring depth was $2.5-3.5 \mathrm{~m}$ on both sides of the pillar at a $45^{\circ}$ syncline. The boreholes on both sides crossed in the middle to ensure that the entire transverse range of the pillar was drilled. The cores were arranged in order after being taken out and processed into standard rock specimens for laboratory tests. The coring process is shown in Figure 9.

\subsection{Results}

3.2.1. Experimental Results of Water Effects. The saturated water content of the gypsum rock was $10.05 \%$. It reaches saturation within $48 \mathrm{~h}$. The wave velocity of the specimens under different immersion times was measured. After reaching the saturation state, the wave velocity fluctuated in the range of $2100-2300 \mathrm{~m} / \mathrm{s}$. Throughout the immersion period, the specimens showed no obvious disintegration. However, in later stages of immersion ( $>90$ days), the surface and edges of the specimens showed obvious exfoliation and slagging. Figure 10 shows the uniaxial compressive stress-strain curves of the gypsum rock specimens with different immersion times. As the immersion time increased, the compression of the specimen increases significantly; the uniaxial compressive strength decreases clearly, and the strain corresponding to the peak strength increases clearly. The compressive strength of the specimens showed obvious small fluctuations before reaching the peak strength.

The strength-weakening rate for the uniaxial compressive strength of gypsum rock is given by

$$
\eta_{\mathrm{Water}}=\frac{\sigma_{c}-\sigma_{\mathrm{Water}}}{\sigma_{c}} \times 100 \%
$$

where $\sigma_{c}$ is the natural compressive strength of the gypsum rock $(\mathrm{MPa})$ and $\sigma_{\text {Water }}$ is the compressive strength of the gypsum rock with different immersion times $(\mathrm{MPa})$.

Figure 11 indicates the variation in the uniaxial compressive strength and strength-weakening rate of gypsum rock specimens with different immersion times. As the immersion time increased, the uniaxial compressive strength and strength-weakening rate decreased and increased, respectively. Each showed a rapid change, followed by a slow change and then a stable state. Water had a greater effect on the strength initially and less at later stages. The maximum strength-weakening rate was $52.61 \%$ at an immersion time of 120 days. For mining areas that are greatly affected by water, water should be considered as a key factor leading to the destruction of pillars and delayed collapse of a goaf, and targeted prevention and control measures should be taken. 

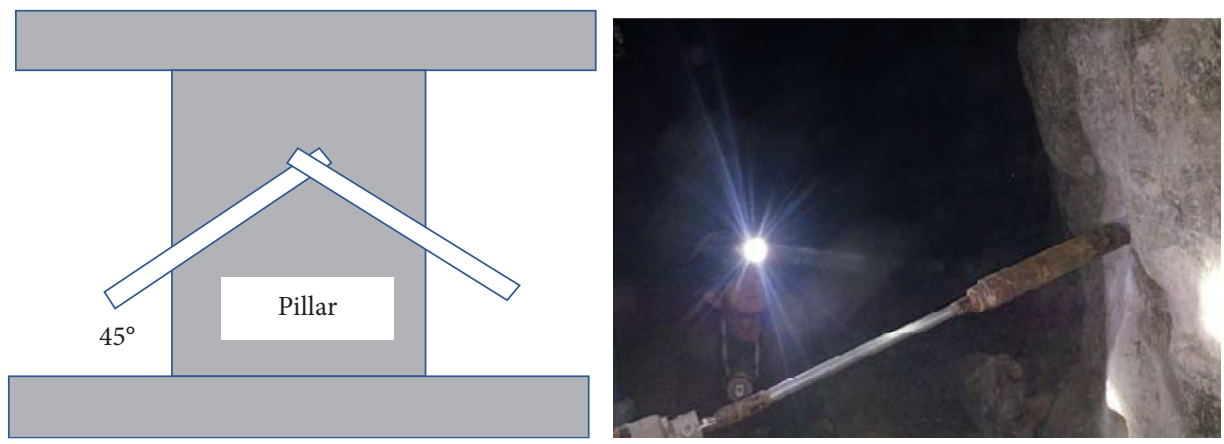

(a)
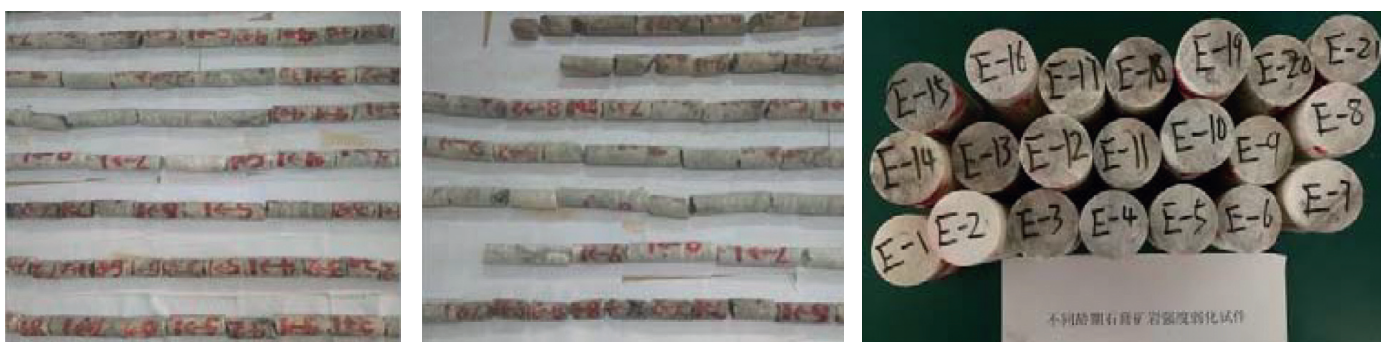

(b)

FIGURE 9: In situ sampling and process. (a) Sampling method in the goaf. (b) Sorting and processing of cores.

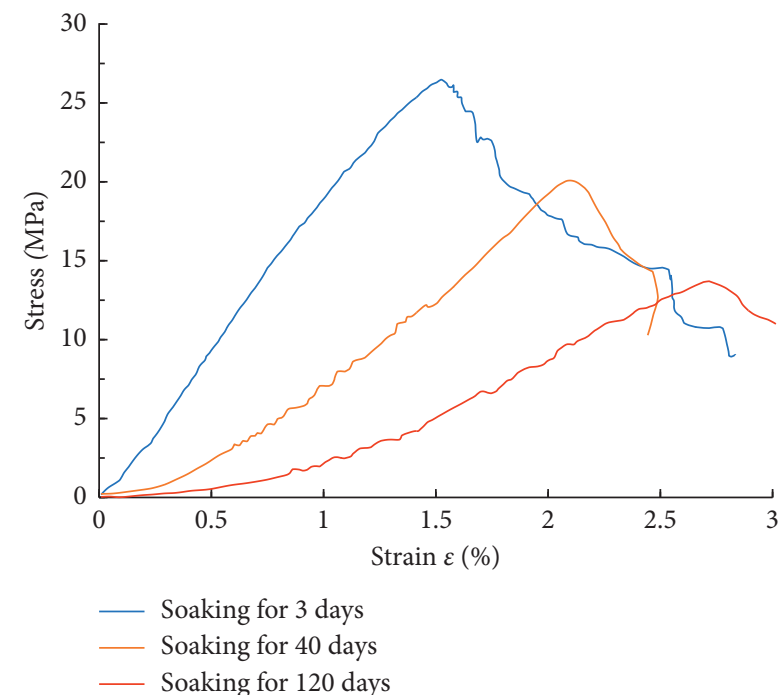

FIgURE 10: Uniaxial compressive stress-strain curve of gypsum rock at different soaking times.

3.2.2. Experimental Results of Temperature Effects. Figure 12 shows the various values of wave velocity of the gypsum rock specimen with the number of temperature cycles. In different states, the wave velocity value of the test specimen shows that the velocity value is not constant. Instead of a steady increase or decrease, the results show a fluctuating change, but the overall trend is downward. The wave velocity changes for the first three cycles are not obvious. After 3-10 cycles, the wave velocity decreased by $500-900 \mathrm{~m} / \mathrm{s}$ but there is a certain fluctuation. After 10 cycles, the wave velocity tended to stabilize, although it still

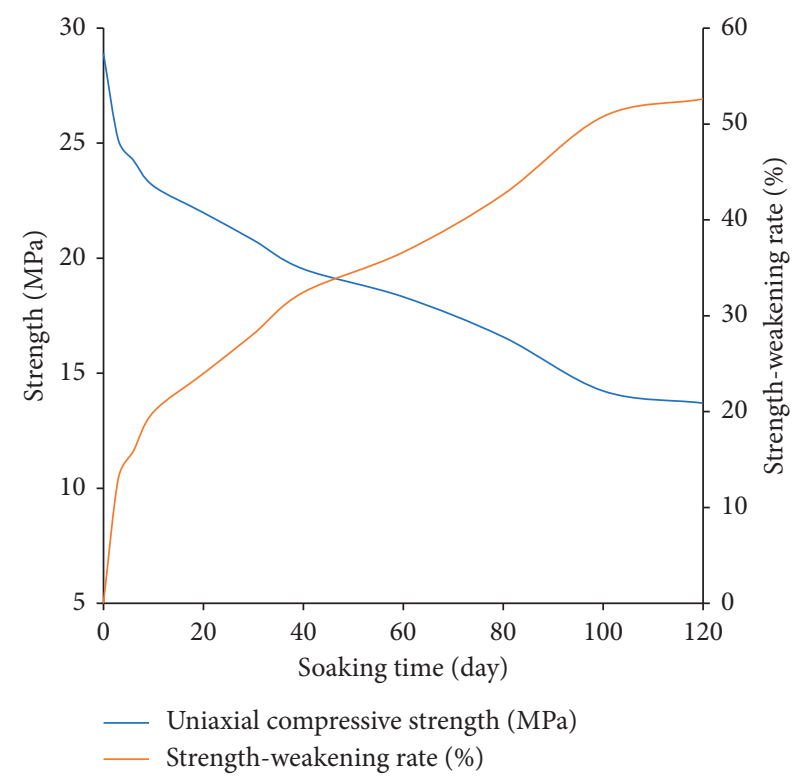

FIGURE 11: Strength and strength-weakening rate of gypsum at different soaking times.

showed some fluctuation. As the number of temperature cycles increased, the wave velocity initially remained stable before rapidly declining and then stabilizing again. The variation range was more than $35 \%$.

Figure 13 shows the uniaxial compressive stress-strain curves of the gypsum rock specimens with different amounts of temperature cycles. With the number of temperature cycles, the compressive stress of the specimens increases clearly. This indicates that the internal microstructure of the 


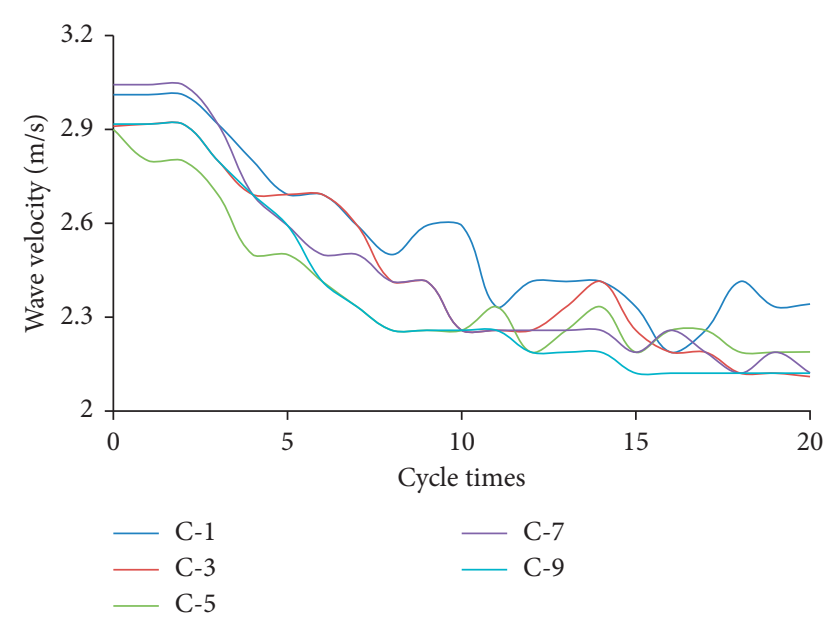

FIGURE 12: Wave velocity curves of specimens with different temperature cycles.

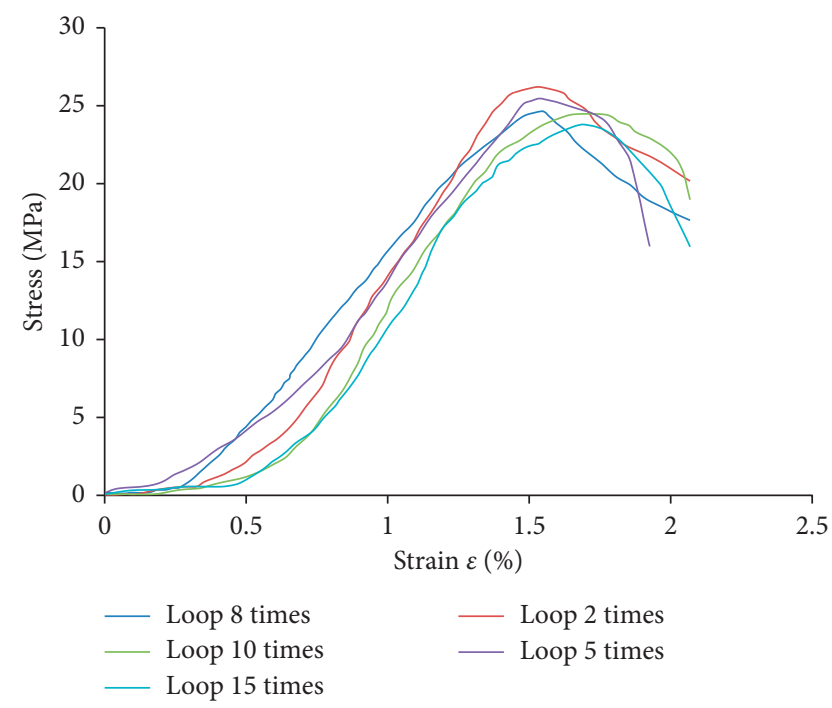

FIGURE 13: Uniaxial compressive stress-strain curves at different temperature cycles.

gypsum ore and rock was expanded and extended by the action of temperature cycling. After more than 10 temperature cycles, the uniaxial compressive stress-strain curve showed obvious fluctuations. As the number of temperature cycles increased, the strength decreased overall, but the range of the decrease was small. The uniaxial compressive strength was $24.53 \mathrm{MPa}$ after 15 cycles.

The strength-weakening rate for the uniaxial compressive strength of gypsum rock subjected to temperature cycles is given by

$$
\eta_{\mathrm{Tem}}=\frac{\sigma_{c}-\sigma_{\mathrm{Tem}}}{\sigma_{c}} \times 100 \%,
$$

where $\sigma_{T \mathrm{em}}$ is the compressive strength of the gypsum rock with different temperature cycles $(\mathrm{MPa})$.

Figure 14 shows the variations in the uniaxial compressive strength and strength-weakening rate of gypsum rock specimens with different temperature cycles. As the number of

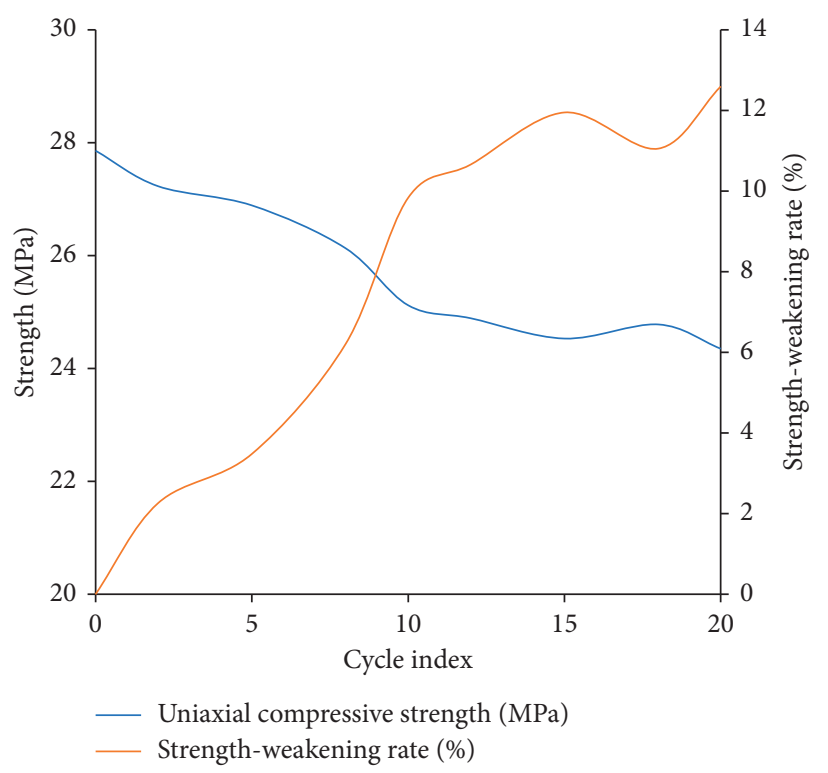

FIgURE 14: Uniaxial compressive strength and strength-weakening curves with different temperature cycles.

temperature cycles increased, the uniaxial compressive strength decreased, and the strength-weakening rate increased. After 20 cycles, the maximum strength-weakening rate was $12.60 \%$, which is relatively low. This indicates that temperature cycles do not have an obvious effect on the strength of gypsum rock, so they do not significantly affect the lag collapse of gypsum mine goafs. Apart from the lax sealing of some mining areas, gypsum mine goafs are generally sealed quite well. Thus, a goaf can be regarded as a closed space with constant temperature and humidity. Temperature cycles should have a relatively small strength-weakening effect on the gypsum rock. Therefore, the seasonal temperature change can be considered an influencing factor for the lagging collapse of goafs in unsealed gypsum mines.

3.2.3. Experimental Results of Time Effects. The gypsum pillars in the goaf were $4-6 \mathrm{~m}$ wide. To study the strengthweakening rate at different pillar depths, the cores at depths of $0.5,1.5$, and $2.5 \mathrm{~m}$ were processed into standard specimens. To standardize the specimens, the precision of the depth had to be within $0.2 \mathrm{~m}$. The uniaxial compressive strength was tested in a laboratory. To eliminate the error, the average peak strength of several specimens was taken as the final strength for different ages and pillar depths. Figure 15 shows the variation in the peak strength.

The following characteristics and laws were obtained:

(1) With increasing pillar depth, the uniaxial compressive strength gradually increased, and the strain corresponding to the peak strength gradually decreased. This trend became more obvious with increasing age. The gypsum rock was stronger and close to the pillar surface $(0.5 \mathrm{~m}$ depth $)$ than deep within the pillar ( $2.5 \mathrm{~m}$ depth) with increasing age. 


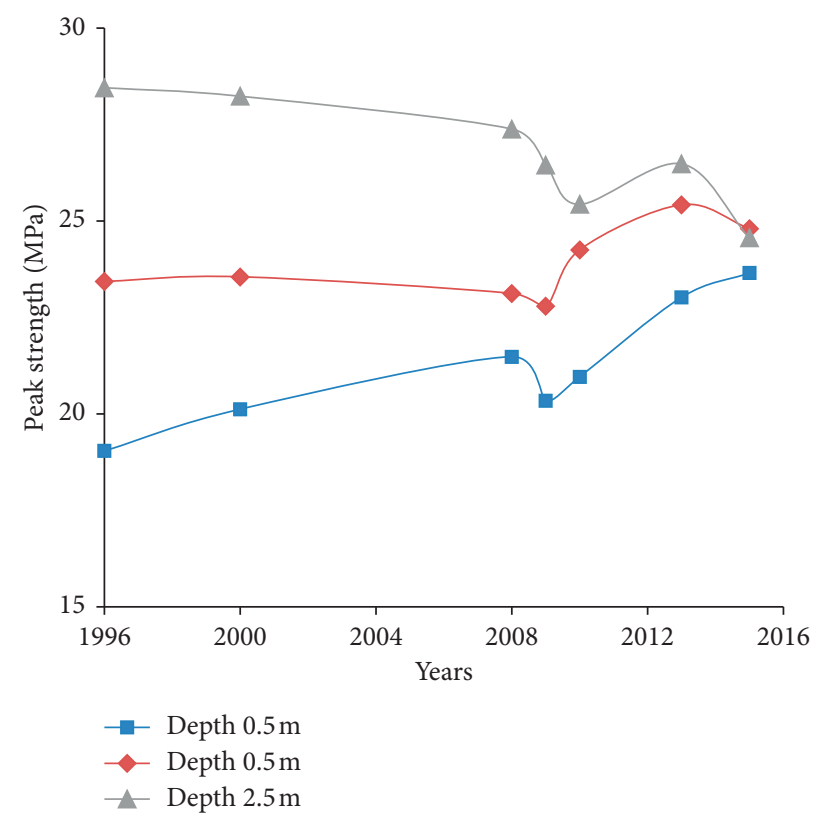

Figure 15: Variation in the peak strength of gypsum rocks at different ages and depths.
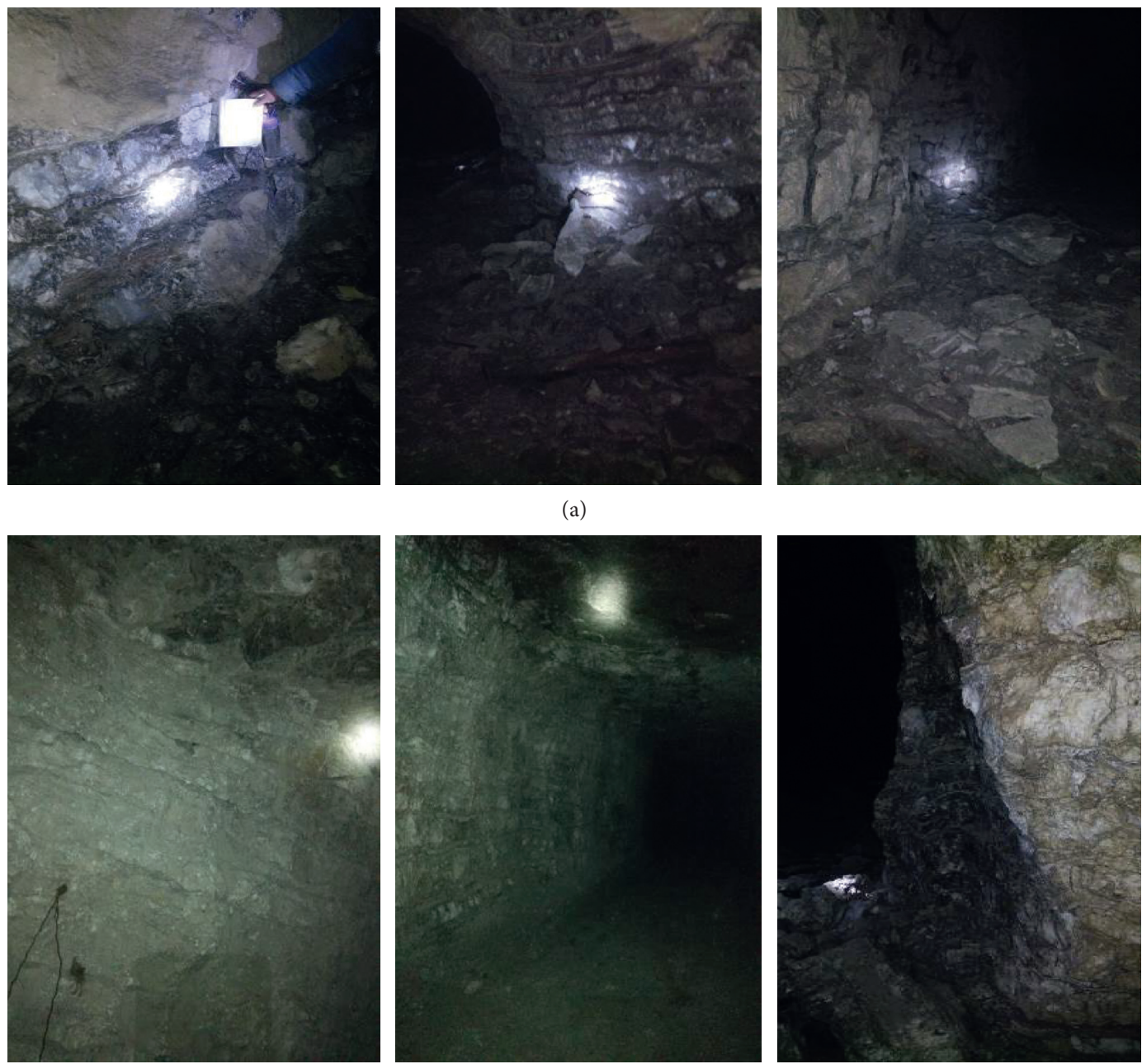

(a)
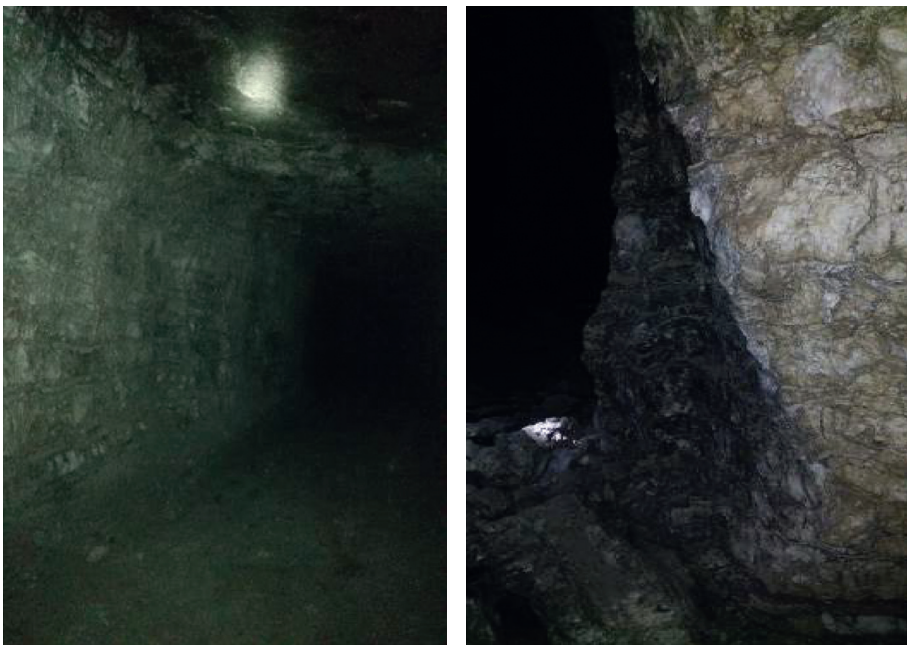

(b)

Figure 16: On-site photos of mine pillars in the goaf. (a) 1996. (b) 2015. 


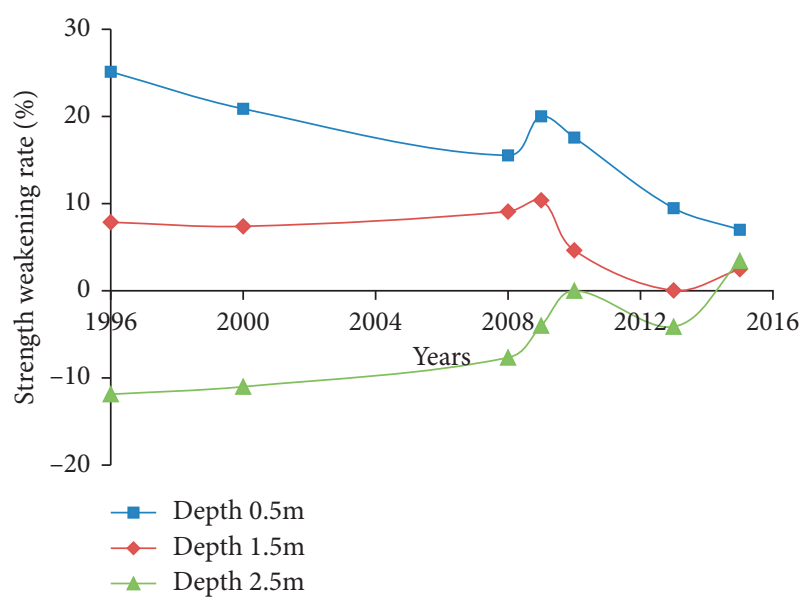

FIGURE 17: Strength-weakening rate of gypsum rock at different ages.

(2) The strength of the gypsum rock greatly differed at pillar depths of 1.5 and $2.5 \mathrm{~m}$ with increasing age. The difference gradually increased with age (e.g., before 2015). However, the strength showed little difference at the pillar depths of 1.5 and $2.5 \mathrm{~m}$ for younger pillars (e.g., after 2015).

These can be explained as follows:

(1) With increasing age, the influences of water, temperature, disturbances, and weathering on the pillar surface increased, and joints and fissures in the gypsum rock developed. Phenomena such as breakage, expansion, and spalling were observed on-site, as shown in Figure 16. When the cores were taken, the gypsum rock had low integrity near the pillar surface, and few cores had a length greater than $10 \mathrm{~cm}$. These reasons led to the increased compaction and decreased strength of the gypsum rock near the pillar surface, which only increased with age.

(2) Under the long-term stress of overlying strata, the gypsum rock deep in the pillar will creep continuously. Before failure and instability occur, the continuous creep will increase the compaction and strength of the gypsum rock. Meanwhile, weathering of the gypsum rock near the pillar surface will reduce the effective support area of the pillar and increase the peak stress deep within the pillar. During coring, some pillars showed obvious obstructions to drilling. The increased stress gradually increased the compaction and strength of the gypsum rock (i.e., plastic hardening). These reasons explain the increased strength of the gypsum rock deep within the pillar with increasing age.

(3) New goafs had little time for weathering and creep, which explains the little change in strength for these samples.

The weakening rate for the uniaxial compressive strength of gypsum rock at different ages is given by

$$
\eta_{\mathrm{Tem}}=\frac{\sigma_{t}-\sigma_{c}}{\sigma_{c}} \times 100 \%,
$$

where $\sigma_{t}$ is the compressive strength of gypsum rock (MPa).

Figure 17 shows the variation in the strength-weakening rate of gypsum rock specimens with different ages and depths. Near the pillar surface (depth of less than $1.5 \mathrm{~m}$ ), the strength-weakening rate increased with age. Deep within the pillar, the strength-weakening rate showed the opposite trend. The maximum strength-weakening rate was $25.13 \%$ (1996), which is relatively low. This is the main reason for the long-term stability of well-sealed goafs, which may not collapse for several years or even decades.

\section{Conclusions}

(1) Two conditions must be satisfied to ensure the stability of the room pillar structure: the pillar is larger than the limit size, and the room is less than the limit span. If these conditions are not met, rock collapse and instability will occur due to pillar or room failure. Pillar failure has a large effect on instability and collapse.

(2) Water has a significant influence on the strength of gypsum rock. The strength-weakening rate of specimens was $52.61 \%$ after immersion in water for 120 days. This indicates that water penetration or flooding can easily destabilize a large-area goaf.

(3) The temperature cycles indicated little effect on the strength of gypsum rock. However, changes in temperature often affect the relative humidity. Therefore, it is a major factor for pillar failure in unsealed goafs.

(4) The gypsum rock near the pillar surface is gradually weathered over time, and it loses its bearing capacity. The supporting pressure is transferred deep within the pillar, so the effective support capacity gradually decreases over time.

\section{Data Availability}

The data used to support the findings of this study are available from the corresponding author upon request.

\section{Conflicts of Interest}

The authors declare that there are no conflicts of interest regarding the publication of this paper.

\section{Authors' Contributions}

Z.W.D. performed the data analysis and wrote this paper. Z.H.L. helped to perform the experiments and revised this manuscript. L.B.Z., F.X.L., and S.W. guided the data analysis method and supervised the experiments.

\section{Acknowledgments}

This study was supported by the Shandong Provincial Natural Science Fund (ZR2018ZC0740). 


\section{References}

[1] Y. X. Guo, P. Wang, and G. R. Feng, "Experimental study on diffusion process of sulfate ion in cemented gangue backfill material," Advances in Civil Engineering, vol. 2020, Article ID 5846397, , 2020.

[2] C. Ju, Y. S. Liu, Z. Y. Yu, and Y. Z. Yang, "Cement-lime-fly ash bound macadam pavement base material with enhanced early-age strength and suppressed drying shrinkage via incorporation of slag and gypsum," Advances in Civil Engineering, vol. 2019, Article ID 8198021, , 2019.

[3] S. Ma, P. Bao, and N. Jiang, "Experimental study of gypsumconcrete dense-column composite boards with external thermal insulation systems," Applied Sciences, vol. 10, no. 6, p. 1976, 2020.

[4] K. Kubicka, U. Pawlak, and U. Radoń, "Influence of the thermal insulation type and thickness on the structure mechanical response under fire conditions," Applied Sciences, vol. 9, no. 13, p. 2606, 2019.

[5] N. Zhou, H. Yan, S. Jiang, Q. Sun, and S. Ouyang, "Stability analysis of surrounding rock in paste backfill recovery of residual room pillars," Sustainability, vol. 11, no. 2, p. 478, 2019.

[6] B. Chen, S. C. Zhang, and Y. Y. Li, "Physical simulation study of crack propagation and instability information discrimination of rock-like materials with fault," Arabian Journal of Geosciences, vol. 966, 2020.

[7] S. Wei, C. Wang, Y. Yang, and M. Wang, "Physical and mechanical properties of gypsum-like rock materials," Advances in Civil Engineering, vol. 2020, pp. 1-17, 2020.

[8] J. Huang, C. Tian, L. Xing, Z. Bian, and X. Miao, "Green and sustainable mining: underground coal mine fully mechanized solid dense stowing-mining method," Sustainability, vol. 9, no. 8, p. 1418, 2017.

[9] T. J. Zhang, M. K. Pang, and X. F. Zhang, "Determining the seepage stability of fractured coal rock in the karst collapse pillar," Advances in Civil Engineering, vol. 2020, Article ID 1909564, , 2020.

[10] S. Chen, Z. Du, Z. Zhang, H. Zhang, Z. Xia, and F. Feng, "Effects of chloride on the early mechanical properties and microstructure of gangue-cemented paste backfill," Construction and Building Materials, vol. 235, Article ID 117504, 2020.

[11] T. J. Tan, Z. Yang, F. Chang, and H. Zhao, "Prediction of the first weighting from the working face roof in a coal mine based on a GA-BP neural network," Applied Sciences, vol. 9, no. 19, p. 4159, 2019.

[12] R. Lu, F. S. Ma, J. Zhao et al., "Monitoring and analysis of stress and deformation features of boundary part of backfill in metal mine," Sustainability, vol. 10, no. 22, p. 733, 2020.

[13] Y. Zhou, M. Li, X. Xu, X. Li, Y. Ma, and Z. Ma, "Research on catastrophic pillar instability in room and pillar gypsum mining," Sustainability, vol. 10, no. 10, p. 3773, 2018.

[14] K. Xia, C. Chen, and Y. Zhou, "Catastrophe instability mechanism of the pillar-roof system in gypsum mines due to the influence of relative humidity," International Journal of Geomechanics, vol. 19, no. 4, Article ID 6019004, 2019.

[15] J.-A. Wang, D. Z. Li, and X. C. Shang, "Creep failure of roof stratum above mined-out area," Rock Mechanics and Rock Engineering, vol. 45, no. 4, pp. 533-546, 2012.

[16] L. Chen, Z. Zhou, C. Zang, L. Zeng, and Y. Zhao, "Failure pattern of large-scale goaf collapse and a controlled roof caving method used in gypsum mine," Geomechanics and Engineering, vol. 18, no. 4, pp. 449-457, 2019.
[17] X. Xu, Y. Zhou, and S. Pang, "Analysis of catastrophic instability of plastic supporting system in old goaf of gypsum mine," Chinese Journal of Rock Mechanics and Engineering, vol. 37, no. 11, pp. 2548-2555, 2018.

[18] K. V. Jessu and A. J. S. Spearing, "Direct strain evaluation method for laboratory-based pillar performance," Journal of Rock Mechanics and Geotechnical Engineering, vol. 11, no. 4, pp. 860-866, 2019.

[19] C. Zhang, X. Yang, G. Ren, B. Ke, and Z. Song, "Instability of gypsum mining goaf under the influence of typical faults," IEEE Access, vol. 7, pp. 88635-88642, 2019.

[20] M. Zielińska and M. Rucka, "Non-destructive assessment of masonry pillars using ultrasonic tomography," Materials, vol. 11, no. 12, p. 2543, 2018.

[21] W. J. Xie and C. Gong, "Experimental study on creep characteristics of red sandstone under step loading," Journal of Safety Science and Technology, vol. 13, no. 6, pp. 34-39, 2017.

[22] B. Shen, B. Poulsen, X. Luo, J. Qin, R. Thiruvenkatachari, and Y. Duan, "Remediation and monitoring of abandoned mines," International Journal of Mining Science and Technology, vol. 27, no. 5, pp. 803-811, 2017.

[23] B. Pouthors, M. Khanal, and A. M. Rao, "Mine overburden dump failure: a case study," Geotechnical and Geological Engineering, vol. 32, no. 2, pp. 297-309, 2014.

[24] Z. Zhou, H. Zang, W. Cao, X. Du, Lu Chen, and C. Ke, "Risk assessment for the cascading failure of underground pillar sections considering interaction between pillars," International Journal of Rock Mechanics and Mining Sciences, vol. 124, 2019.

[25] J. M. Li and G. Y. Li, "The strength and deformation characteristics of saturated weathered granite under freezing and thawing conditions," Journal of Glaciology and Geocryology, vol. 42, no. 2, pp. 1-9, 2020.

[26] Z. Du, S. Chen, J. Ma, Z. Guo, and D. Yin, "Gob-side entry retaining involving bag filling material for support wall construction," Sustainability, vol. 12, no. 16, p. 6353, 2020.

[27] S. Chen, Z. Du, Z. Zhang, D. Yin, F. Feng, and J. Ma, "Effects of red mud additions on gangue-cemented paste backfill properties," Powder Technology, vol. 367, pp. 833-840, 2020.

[28] Y. Yu, S.-E. Chen, K.-Z. Deng, and H.-D. Fan, "Long-term stability evaluation and pillar design criterion for room-andpillar mines," Energies, vol. 10, no. 10, p. 1644, 2017.

[29] J. A. Wang, D. Z. Li, and H. T. Ma, "Study of rheological mechanical model of pillar-roof system in mined-out area," Chinese Journal of Rock Mechanics and Engineering, vol. 29, no. 3, pp. 577-582, 2010.

[30] Y. Zhang, S. Cao, L. Lan, R. Gao, and H. Yan, "Analysis of development pattern of a water-flowing fissure zone in shortwall block mining," Energies, vol. 10, no. 5, p. 734, 2017.

[31] X. Shao, X. Li, L. Wang et al., "Study on the pressure-bearing law of backfilling material based on three-stage strip backfilling mining," Energies, vol. 13, no. 1, p. 211, 2020.

[32] W. Cao, X. Wang, P. Li, D. Zhang, C. Sun, and D. Qin, "Wide strip backfill mining for surface subsidence control and its application in critical mining conditions of a coal mine," Sustainability, vol. 10, no. 3, p. 700, 2018.

[33] G. Song and S. Yang, "Probability and reliability analysis of pillar stability in South Africa," International Journal of Mining Science and Technology, vol. 28, no. 4, pp. 715-719, 2018.

[34] O. Vardar, F. Tahmasebinia, C. Zhang, I. Canbulat, and S. Saydam, "A review of uncontrolled pillar failures," Procedia Engineering, vol. 191, pp. 631-637, 2017. 
[35] Z.-H. Xu, G.-L. Feng, Q.-C. Sun, G.-D. Zhang, and Y.-M. He, "A modified model for predicting the strength of dryingwetting cycled sandstone based on the P-wave velocity," Sustainability, vol. 12, no. 14, p. 5655, 2020.

[36] W. Guan, D. Zhang, and Y. Wen, "Influence of curing humidity on the compressive strength of gypsum-cemented similar materials," Advances in Materials Science and Engineering, vol. 2016, Article ID 7062624, , 2016.

[37] S. Mohammadhossein and J. Vitton Stanley, "Laboratory study of gypsum dissolution rates for an abandoned underground mine," Rock Mechanics and Rock Engineering, vol. 52, no. 7, pp. 2053-2066, 2019.

[38] S. Mohammadhossein and J. Vitton Stanley, "Analysis of drying and saturating natural gypsum specimens for mechanical testing," Journal of Rock Mechanics and Geotechnical Engineering, vol. 11, no. 2, pp. 219-227, 2019.

[39] Z. Du, S. Chen, S. Wang, R. Liu, D. Yao, and H. S. Mitri, "Influence of binder types and temperatures on the mechanical properties and microstructure of cemented paste backfill," Advances in Civil Engineering, vol. 2021, Article ID 6652176, 10 pages, 2021.

[40] F. Krause, B. Renner, F. Coppens, J. Dewanckele, and M. Schwotzer, "Reactivity of gypsum-based materials subjected to thermal load: investigation of reaction mechanisms," Materials, vol. 13, no. 6, p. 1427, 2020.

[41] T. Meng, Y. Hu, R. Fang, Q. Fu, and W. Yu, "Weakening mechanisms of gypsum interlayers from Yunying salt cavern subjected to a coupled thermo-hydro-chemical environment," Journal of Natural Gas Science and Engineering, vol. 30, pp. 77-89, 2016.

[42] S. Chen, D. Zhang, T. Shang, and T. Meng, "Experimental study of the microstructural evolution of glauberite and its weakening mechanism under the effect of thermal-hydrological-chemical coupling," Processes, vol. 6, no. 8, p. 99, 2018.

[43] A. Christophe, H. Françoise, and S. Claudia, "The aging of gypsum in underground mines," Engineering Geology, vol. 74, pp. 183-196, 2004.

[44] Z. Peter, D. Heather, and S. Daniel, "Influence of longwall mining on the stability of gas wells in chain pillars," International Journal of Mining Science and Technology, vol. 30, no. 1, pp. 3-9, 2020.

[45] C. Riccardo, R. Nova, and O. Gianmarco, "Evaluation and remediation of an abandoned gypsum mine," Journal of Geotechnical and Geoennironmental Engineering, vol. 136, no. 4, pp. 629-639, 2010.

[46] H. Sylke, A. Viktoria, and R. Franz, "Hydrogeology in gypsum karst as base for geotechnical long term prognosis in mining plants," Grundwasser, vol. 19, no. 1, pp. 39-49, 2014.

[47] W. Ge, M. Chen, Y. Jin et al., "Analysis of the external pressure on casings induced by salt-gypsum creep in build-up sections for horizontal wells," Rock Mechanics and Rock Engineering, vol. 44, no. 6, pp. 711-723, 2011. 